\title{
Thawing of permafrost soils under the water intake facility (the Taas-Yurekh river, Yakutia, Russia)
}

\author{
Igor Fomenko ${ }^{1}$, Daria Shubina ${ }^{1, *}$, Denis Gorobtsov ${ }^{1}$ and Olga Sirotkina ${ }^{2}$ \\ ${ }^{1}$ Russian State Geological Prospecting University n.a. S. Ordzhonikidze, Moscow, Russian Federation \\ ${ }^{2}$ Moscow state University n.a. M. V. Lomonosov, Moscow, Russian Federation
}

\begin{abstract}
Infrastructure development and oil field exploitation are facing great difficulties. This is caused by the engineering geological conditions changing and transformation of the upper part of the section due to the anthropogenic influence. The article contains the results of researching permafrost soils conditions in the bucket-type water intake facility foundation near the Taas-Yurekh River, Yakutia, Russia (the eastern block of Srednebotuobinskoye oil/gas-condensate field). As a result of the research area engineering geological conditions analysis, the geotechnical scheme was constructed, and on the base of it the soils thawing depth mathematical modelling due to the water heating influence was performed. The soils thawing depth calculation due to the heating of the water in the reservoir was performed with the TEMP/W software of GeoStudio, which is based on the finite element method. The forecast for the end of the facility lifetime was based on the temperature measurements in the reservoir and the soil surface. The calculations results show that the maximum thawing depth due to the water heating influence will be 36 meters with the lower border temperature of $-1{ }^{\circ} \mathrm{C}$, and it decreases to 16 meters with $-10^{\circ} \mathrm{C}$ lower border temperature.
\end{abstract}

\section{Introduction}

Arctic landscapes with hydrological systems and ecosystems present challenges for building of infrastructures. Permafrost temperature and active layer thickness (ALT) are key indicators of changes in permafrost conditions. Permafrost is defined as earth materials (e.g., soil, rock) that exist at or below $0^{\circ} \mathrm{C}$ continuously for at least two consecutive years [1].

The research purpose is the thawing depth calculations under the designed containment pond in the eastern block of Srednebotuobinskoye oil/gascondensate field for 50 years life time.

Infrastructure development and oil field exploitation in the permafrost regions which according to [2] covered the $23.9 \%$ of the northern hemisphere territories are concerned with great difficulties due to the engineering geological conditions changing and transformation of the upper part of the section under the anthropogenic influence. The points of heat exchange modelling between permafrost soils and different heat producing engineering systems are reviewed in the $[3,4,5,6,7,8]$ and etc.

The lythotechnical systems industrial component thermophysical properties differ a lot from the natural component $[9,10]$. The thermal gradient that occurs in this border is the cause of different geocryological processes [11]. The permafrost soil thawing under the constructions causes additional differential settlements of soil massifs [11]. After the following soils freezing the heaving is possible[6]. Thus, while constructing the lythotechnical systems in the permafrost regions the constructive peculiarities and their heating interaction with the foundation soils must be taken into account [6].

Srednebotuobinskoye oil/gas-condensate field (OGCF) was discovered in 1970 and brought into pilot production in 2013. At present moment according to its reserves value the field is classified as the subsoil plot of the Federal importance and one of the largest fields in the Eastern Siberia. It belongs to Lena-Tungussian oiland-gas province.

Researches dedicated to the cryological conditions dynamics studying are represented in $[1,12,13]$.

\section{Methods \& object}

\subsection{Field of Study}

According to the main tectonic elements the field can be divided into three big blocks: Central, North and Eastern blocks Srednebotuobinskoye (Fig. 1).

\footnotetext{
* Corresponding author: ddshubina@gmail.com
} 


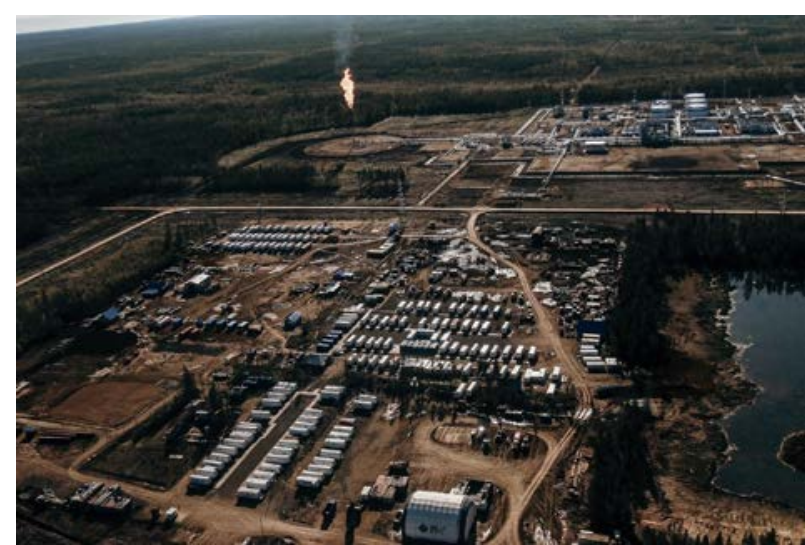

Fig. 1. Common view of Srednebotuobinskoye OGCF Eastern block facilities.

The projected water intake of the field's Eastern block is located in the Republic of Sakha (Yakutia), Mirny district, $130 \mathrm{~km}$ southwest of the city of Mirny and $140 \mathrm{~km}$ northwest of the city of Lensk, $15 \mathrm{~km}$ northwest of Taas -Yuryakh, on the left bank of the Taas Yurekh river.

Water intake facility consists of level 1 pump station, filled gathering pond, weir inlet, water outlet, offtake regulator (Fig.2).

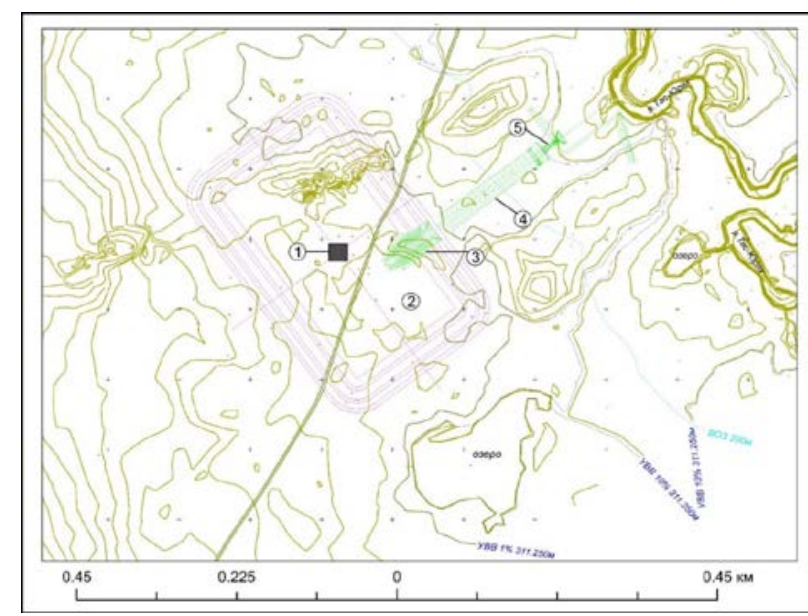

Fig. 2. Water intake facilities location plan Constructions: 1 Level 1 pump station, 2 - filled gathering pond, 3 - weir inlet, 4 - water outlet, 5 - offtake regulator.

Hydrographic characteristics are represented by the Taas-Yurekh river and some smaller. The rivers nourishment is mainly snowy. The creeks and rivers valleys are water-logged and about $10 \%$ of described territory is covered with swamps and water-logged territories. The freezeup occurs in the first decade of December and the river breakeup - in the end of April beginning of May. The biggest ice thickness is about 120 sm.

The relief can be described as hilly steppe plain dissected by dense network of intermittent streams. Absolute relief elevations are $300-390 \mathrm{~m}$, relative altitudes - 30-50 m.The geological section of the projected water intake site is composed of Middle Upper Cambrian (Verkholenskaya suite) deposits represented by siltstones, marls, chocolate-brown and greenish-gray mudstones, and rarely sandstones, interlayered with afanite limestones and micaceous siltstones, the presence of pink gypsum interlayers is typical in the lower part of the suite. Overlapping Quaternary sediments are divided into genetic types (eluvial, palustrian, alluvial) and belong to the Upper Neopleistocene-Holocene. The main feature of the engineering geological conditions of the field is the widespread development of permafrost occurring to a depth of $400 \mathrm{~m}$ [14].

The region has a severely continental climate, with harsh, long winters and short, hot summers. The main factors affecting the severity of the climate are the deep continental inland position and the mountainous framing of the plains from the east, southeast and south, which impede the penetration of moist air from the Pacific Ocean. The particular severity of the natural conditions is determined by winter with an average duration of 7 months with clear weather and low temperatures. The average monthly air temperature in January ranges from $-28^{\circ} \mathrm{C}$ to $-40^{\circ} \mathrm{C}$. Quite often negative temperatures in winter reach minus $53-57^{\circ} \mathrm{C}$.

Spring and autumn are practically absent. In summer, hot days (temperature rises up to $+30^{\circ} \mathrm{C}$ ) are replaced by cold nights. The average monthly air temperature in July in Mirny district varies from $+12^{\circ} \mathrm{C}$ to $+18^{\circ} \mathrm{C}$, and the maximum is $+33^{\circ} \mathrm{C}-+35^{\circ} \mathrm{C}$. There is little rainfall in the area, the soil dried over the summer is slightly moistened and freezing at the end of September leaves under dry snow. Snowfalls are most characteristic for October-November.

The engineering-geological and geocryological conditions analysis made it possible to distinguish within the future foundation pit of the water intake facility (Fig. 3 ), which is the most dangerous from the point of view of geocryological processes developing risks during its operation.

Engineering geological elements (numbers in white circles): seasonally thawed soils $-1 *$ soil and plant layer $(\mathrm{pH}), 2 *$ medium-decomposed peat, $(\mathrm{bH}), 4 *$ brown loam, layered cryogenic structure, soft plastic in the melt state, (aIII-H), with low ice content, $5 *$ - loam brown with interlayers of gray, layered, rarely massive, cryogenic structure, melt-flowing with interlayers of fluid-plastic, (aIII-H), low ice content, with interlayers of ice, $6 *$ - brown loam with interlayers of gray, layered, less often massive, cryogenic structure, in mealty condition fluid with interlayers of fluid-plastic, (aIII-H), with high ice content ; permafrost soils - 4- brown loam, layered cryogenic structure, soft-melt in thawed state, soft-elastic interlayers, incl. gravel and crushed stone, (aIII-H), low ice content, frozen, 5- brown loam with interlayers of gray, layered, rarely massive, cryogenic structure, fluid in melt condition with interlayers of fluid-plastic, incl. gravel and crushed stone, (aIII-H), low ice content with interlayers of ice, frozen, 8- gravel and pebble soil with sandy loamy aggregate of plastic consistency, (aIII-H), low ice content, less often icy, 9gravel-pebble soil with sandy loamy aggregate consistency, with interlayers of gravelly sand, (aIII-H), high ice content, 10- ice (aIII-H), 11- variegated loam (from red-brown to bluish-gray), layered cryogenic structure, solid with semi-solid interlayers, with incl. 


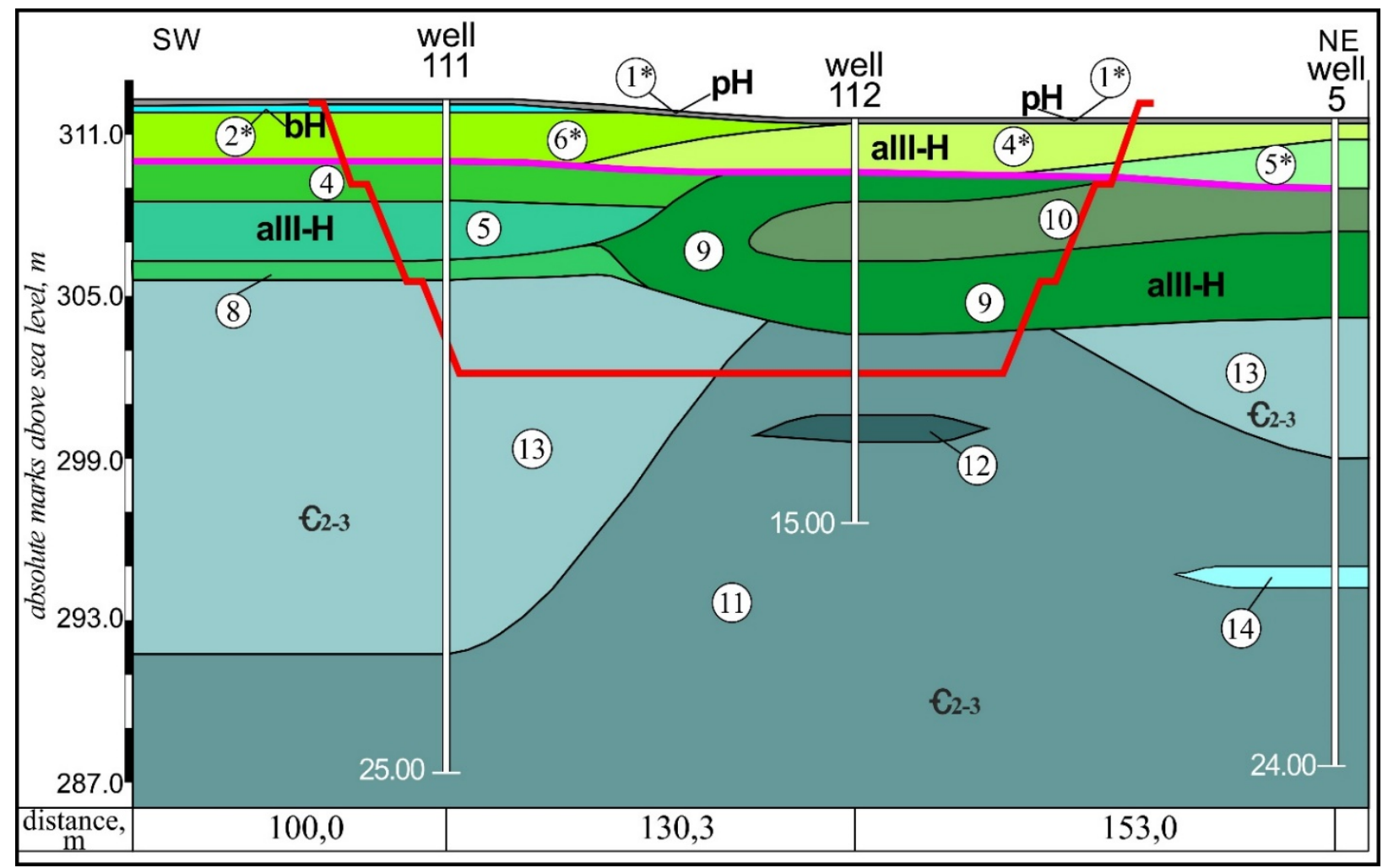

Fig. 3. Schematic engineering-geological section through the reservoir foundation.

wood and gravel, (€2-3), low ice content, 12-woodgravel soil with loamy aggregate of semi-solid and solid consistency, (€2-3), low ice content, 13-variegated clay loam (from red-brown to bluish-gray), layered cryogenic structure, in a thawed state fluid with interlayers of soft plastic, incl. wood and gravel, (€2-3), low ice content, 14-marl strongly cracked, sometimes decays on gravelly soil with loamy aggregate, $(€ 2-3)$, low ice content.

The red line is the profile of the pit, the purple line is the border of permafrost soils.

\subsection{The calculation of soils thawing depth caused by water in the containment pond}

Numerical methods are the most effective and universal in freezing-thawing models researches. A large number of works are devoted to the development of difference methods for solving the heat equation [15, 16, 17]. Currently, there are the following difference methods for solving problems of the Stefan type: front localization method by a difference grid node, frontal rectification method, smoothing coefficient method, and end-to-end computation schemes [15].

In this work the calculation of the soils thawing depth from the effects of water in the containment pond was performed using the TEMP / W software from the GeoStudio complex, based on the finite element method [18]. This program was developed in Canada, which is not surprising since more than half of its territory as in Russia is occupied by permafrost soils. Of particular interest within the framework of this article are the works of Norbert Morgenstern [19-23] better known in our country in connection with the slope stability calculations [24, 25]. He began to study permafrost soils in the 70 s of the last century in connection with the development of the Arctic territories.

TEMP / W can be used to simulate surface temperature changes due to both climate change and human impact. This program allows solving various problems of thermal physics, including freezing and thawing processes in the soil base of the studied objects [18].

The main assumption of TEMP / $\mathrm{W}$ is that the moisture content does not change during the problem solution that is the total moisture content is fixed and the ratio of ice to water in the soil is determined by its total volume moisture.

The TEMP / W algorithm uses volumetric heat capacity of the soil, which can be approximated from the density of the soil skeleton and the sum of the specific heat capacities of its various components (soil particles, water and ice). The general equation for estimating volumetric heat capacity [23]:

$$
\mathrm{C}=\mathrm{c} * \gamma=\gamma_{\mathrm{d}}\left[\mathrm{c}_{\mathrm{s}}+\mathrm{c}_{\mathrm{w}} * \mathrm{w}_{\mathrm{u}}+\mathrm{c}_{\mathrm{i}} * \mathrm{w}_{\mathrm{f}}\right]
$$

where: C - volumetric heat capacity of the soil, c specific heat capacity of the soil, $\gamma$ - bulk density of the soil, $\gamma_{d}$ - dry density of the soil, $c_{s}$ - specific heat capacity of soil particle, $\mathrm{c}_{\mathrm{w}}$ - specific heat capacity of water, $c_{i}$ - specific heat capacity of ice, $w_{u}$ - unfrozen water content expressed in \% of dry weight of the soil, $\mathrm{w}_{\mathrm{f}}$ - frozen water content expressed in \% of dry weight of the soil. 
The differential equation used in the TEMP / W statement is as following:

$$
\frac{d}{d x} *\left(k y \frac{d T}{d x}\right)+\frac{d}{d y} *\left(k y \frac{d T}{d y}\right)+Q=\frac{d T}{d t}
$$

where: $\mathrm{T}$ - temperature, $\mathrm{kx}$ - thermal conductivity in the $\mathrm{x}$-direction, ky - thermal conductivity in the y-direction, $\mathrm{Q}$ - applied boundary flux, $\lambda$ - capacity for heat storage, $\mathrm{t}$ - time.

From equation (2) follows that the difference between the heat flux entering the elemental soil volume and leaving it at each moment of time is equal to the change in thermal energy in this elementary soil volume.

At the initial stage a design scheme was created based on the project documentation and engineering geological data

To set the boundary conditions the information about air temperature changing was used:

- on the soil surface;

- on the water surface in a future reservoir;

- on the lower boundary of the study area.

The temperature on the surface of the soil and water was taken on the basis of engineering hydrometeorological surveys, taking into account the annual cycle of temperature fluctuations (fig. 4).

The depth of the calculation area, taking into account the limited service water intake facility life, is conventionally accepted as $100 \mathrm{~m}$.

The initial state of the model was set based on temperature measurements data in wells drilled in the area (up to the investigated depth of $30 \mathrm{~m}$ ). Then the depth of soils thawing from the influence of water in the reservoir was calculated to the facility service lifetime of 50 years in increments of 7.5 years.
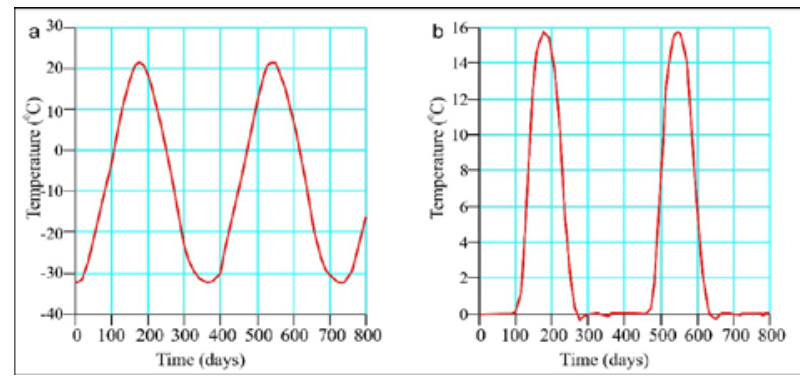

Fig. 4. Temperature on the soil surface (a), temperature in the pond (b).

The depth of the calculation area, taking into account the limited service water intake facility life, is conventionally accepted as $100 \mathrm{~m}$.

The initial state of the model was set based on temperature measurements data in wells drilled in the area (up to the investigated depth of $30 \mathrm{~m}$ ). Then the depth of soils thawing from the influence of water in the reservoir was calculated to the facility service lifetime of 50 years in increments of 7.5 years.

\section{Results and Discussion}

The greatest uncertainty in the calculation scheme construction is associated with setting conditions at its lower boundary [26, 27], with the calculation area depth estimation, with the nature of temperature distribution in the permafrost soils, estimated on the basis of paleoclimatic studies and the thermal properties of soils composing the geological section. The factors mentioned above were not determined for the study site. For this reason a variational approach was used in the calculations, which means that different temperatures were set at the boundary of the computational area.

The predicted soils thawing depth under the storage pond for the final of its lifetime provided that the temperature at the lower boundary is minus 1 degree Celsius is $36 \mathrm{~m}$ (Fig. 5).

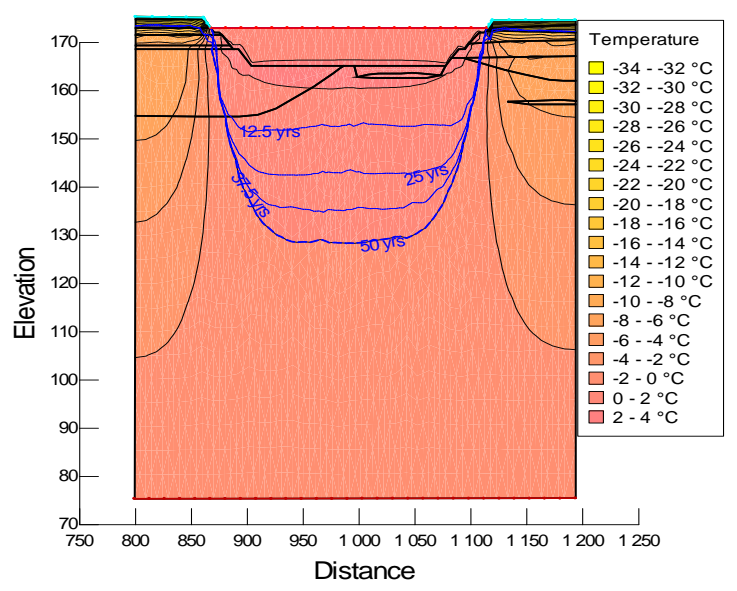

Fig. 5. Forecast for 50 years. The blue dotted line shows the formation of the thawing bowl for each 7.5 years with temperature at the lower boundary of $-1^{\circ} \mathrm{C}$ (thawing depth 36 $\mathrm{m})$.

The predicted soils thawing depth under the storage pond for the final of its lifetime provided that the temperature at the lower boundary is minus 10 degree Celsius is $16 \mathrm{~m}$ (Fig. 6). 


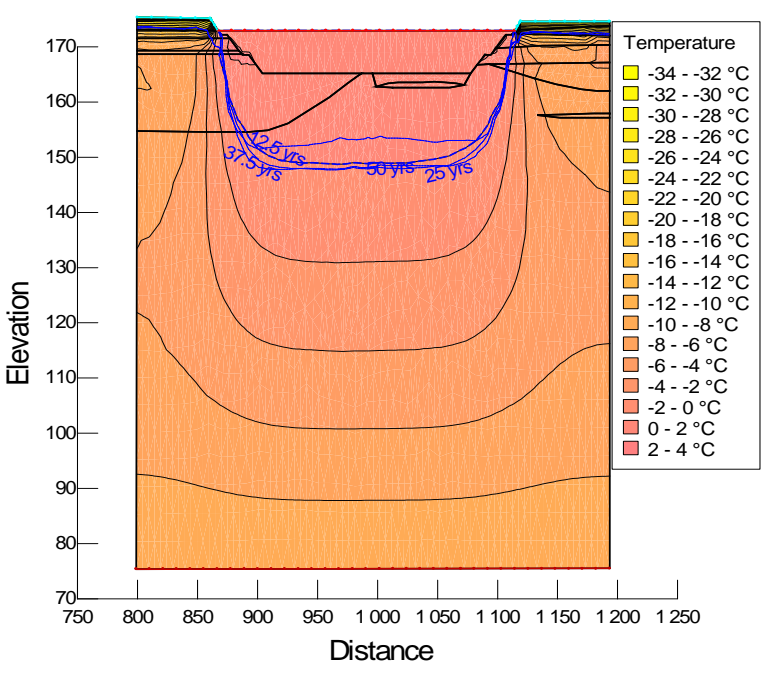

Fig. 6. Forecast for 50 years. The blue dotted line shows the formation of the thawing bowl in time with temperature at the lower boundary of $-10^{\circ} \mathrm{C}$ (thawing depth $16 \mathrm{~m}$ ).

A decrease in temperature at the reservoir's lower boundary leads to a decrease in the thawing depth, but the dependence graph of these values is not linear. Thus, we can assume that there is a temperature at which changes in the lower boundary position will not affect the thawing bowl dimension. Calculations showed that for this section this temperature is close to minus $10^{\circ} \mathrm{C}$ (Fig. 7).

The problem of permafrost soils thawing mathematical modelling in the containment pond foundation is the lack of initial data. It is evaluative. This is due, on the one hand, to the need for schematization and determination of the computational area size, and on the other, to the uncertainty of the initial information, primarily due to the lack of objective data on the thickness, properties and state of permafrost soils. The rate of permafrost thawing was designated by IPCC (2013) as one of the major uncertainties in future climate projections [28].

An additional complicating factor is that the collection, accumulation and analysis of information as a rule is accompanied by measurement errors that distort the limited information about geotechnical conditions. This point is also exacerbated by the spatio-temporal random nature of the factors affecting the object of research.

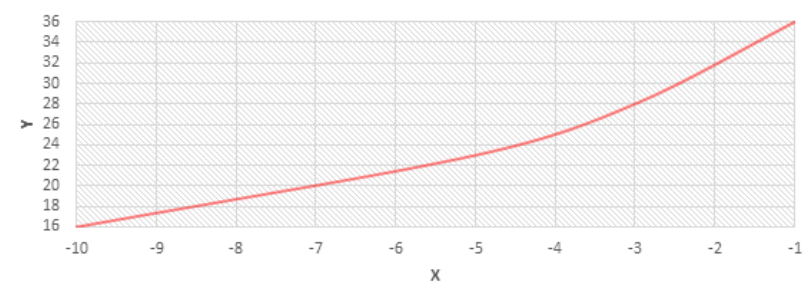

Fig. 7. Dependence of thawing depth $(\mathrm{Y})$ on temperature at the lower boundary $(\mathrm{X})$.

The problem of permafrost soils thawing mathematical modelling in the containment pond foundation is the lack of initial data. It is evaluative. This is due, on the one hand, to the need for schematization and determination of the computational area size, and on the other, to the uncertainty of the initial information, primarily due to the lack of objective data on the thickness, properties and state of permafrost soils. The rate of permafrost thawing was designated by IPCC (2013) as one of the major uncertainties in future climate projections [28].

An additional complicating factor is that the collection, accumulation and analysis of information as a rule is accompanied by measurement errors that distort the limited information about geotechnical conditions. This point is also exacerbated by the spatio-temporal random nature of the factors affecting the object of research.

\section{Conclusions}

The main conclusions from the results of mathematical modelling are the following:

1. The maximum depth of soil thawing because of the water in the containment pond influence will be $36 \mathrm{~m}$ at a temperature at the lower boundary of $-1^{\circ} \mathrm{C}$.

2. At a temperature at the lower boundary of $-10^{\circ} \mathrm{C}$ the thawing depth decreases to $16 \mathrm{~m}$ and after 25 years the equilibrium of the dynamic system under consideration, i.e. the depth of thawing remains constant.

3. The results obtained allow to develop a methodology for studying the permafrost soils on the basis of the thermokarst lakes depth and condition studying, as well as to evaluate the potential thermokarst hazard of the territory.

\section{References}

1. Abernethy, R. \& Ackerman, Steve \& Adler, Robert \& Encarnación, A. \& Aldeco, L.S. \& Alfaro, Eric \& Aliaga-Nestares, V. \& Allan, Richard \& Allan, Rob \& Alves, Lincoln \& Amador, Jorge \& Anderson, James \& Andreassen, Liss Marie \& Argueez, A \& Armitage, C. \& Arndt, Derek \& Avalos, G. \& Azorin-Molina, Cesar \& Báez, Julián. (2018). State of the climate in 2017. Bulletin of the American Meteorological Society. 99. SiS332.

2. Zhang, Tingjun \& Barry, Roger \& Knowles, K. \& Heginbottom, J. \& Brown, Jervon. (2008). Statistics and characteristics of permafrost and ground-ice distribution in the Northern Hemisphere. Polar Geography. 31. 4768. 10.1080/10889370802175895

3. Filimonov, Mikhail \& Vaganova, N.A.. (2013). Simulation of thermal stabilization of soil around various technical systems operating in permafrost. Applied Mathematical Sciences. $7 . \quad 7151-7160$. 10.12988/ams.2013.311669.

4. Gorelik, J.B. \& Romanyuk, S.N. \& Seleznev, A.A.. (2014). Some characteristics of the calculation methods of the frozen soil's thermal state in the flare facility foundation. 18. 57-64.

5. Chao, G., \& Lu, Z. (2019). Frost heaving of foundation pit for seasonal permafrost areas. Magazine 
of Civil Engineering, 86(2), 61. https://doi.org/10.18720/MCE.86.6

6. Teltayev, Bagdat \& Liu, J. \& Suppes, E.A.. (2018). Distribution of temperature, moisture, stress and strain in the highway. Magazine of Civil Engineering. 83. 102113. 10.18720/MCE.83.10.

7. D. Gorobtsov, I. Fomenko, V. Pendin, M Nikulina, Identification of the emergency condition reasons at railway lines that are in difficult geocryological conditions. In Transportation Soil Engineering in Cold Regions (Transoilcold 2019), Springer. (2019)

8. V.Pendin, I. Fomenko, D. Gorobtsov, M. Nikulina, Comprehensive bearing capacity analysis of permafrost railroad leading to tank-car filling rack. In Geotechnics Fundamentals and Applications in Construction: New Materials, Structures, Technologies and Calculations, vol. 2 of Proceedings in Earth and geosciences, CRC Press/Balkema Leiden, The Netherlands,225-230, (2019)

9. Muller, S.W. \& French, H.M. \& Nelson, F.E.. (2008). Frozen in time: Permafrost and engineering problems. 10.1061/9780784409893.

10. Vasilyev, G.P. \& Gornov, V.F. \& Peskov, Nick \& Popov, M.P. \& Kolesova, M.V. \& Yurchenko, V.A.. (2017). Ground moisture phase transitions: Accounting in BHE'S design. Magazine of Civil Engineering. 74. 102-117. 10.18720/MCE.74.9.

11. Regehr, Jonathan \& Milligan, Craig \& Montufar, Jeannette \& Alfaro, Marolo. (2013). Review of Effectiveness and Costs of Strategies to Improve Roadbed Stability in Permafrost Regions. Journal of Cold Regions Engineering. 27. 109-131. 10.1061/(ASCE)CR.1943-5495.0000054.

12. Romanovskii, N. \& Tipenko, Gennadiy \& Buldovich, Sergey \& Sergeev, Dmitry \& Gavrilov, A. \& Romanovsky, Vladimir \& Duxbury, Natalia \& Yoshikawa, K.. (2016). Mathematical Modeling of Climate - Permafrost - Groundwater Dynamics: a Study of Bestyakh Terrace, Lena River, Siberia. XI International Conference On Permafrost Exploring Permafrost in a Future Earth.

13. Sergeev, Dmitry \& Tipenko, Gennadiy \& Romanovsky, Vladimir \& Romanovskii, N.N.. (2003). Evolution of mountain permafrost thickness under the influence of long-term climate fluctuations (results of numerical simulation for condition of Northern Permafrost Zone). 7. 15-22.

14. V.V. Shepelev in Republic Of Sakha (Yakutia). Comprehensive Atlas. (Yakut. aerogeodesy. enterprise, Yakutsk, 2009), pp.26-27

15. 15 A. A. Samarsky, P. N. Vabishchevich. Computational Heat Transfer: Volume 2, The Finite Difference Methodology, 1rd ed. (John Wiley \& Sons, NY, 1995)

16. Vaganova, N.. (2008). Existence of a solution of an initial-boundary value difference problem for a linear heat equation with a nonlinear boundary condition. Proceedings of The Steklov Institute of Mathematics PROC STEKLOV INST MATH. 261. 260-271. 10.1134/S0081543808050209.

17. Bashurov V.V., Vaganova N.A., Filimonov M.Y. Numerical simulation of thermal conductivity processes with fluid filtration in soil // Computational technologies. 2011. V. 16. № 4. P. 3-18

18. Thermal Modeling with TEMP/W (2007). An Engineering Methodology. GEO-SLOPE International Ltd. 2rd Edition, (Calgary, Alberta, Canada)

19. Morgenstern, N. R., Roggensack, W. D., \& Weaver, J. S. (1980). The behavior of friction piles in ice and icerich soils. Canadian Geotechnical Journal, 17(3), 405415.

20. Morgenstern, N.R., and Nixon, J.F. (1975). An analysis of the performance of a warm-oil pipeline in permafrost, Inuvik, N.W.T. Canadian Geotechnical Journal, 12(2): 199-208. doi:10.1139/t75-024.

21. Weaver, J. S., \& Morgenstern, N. R. (1981). Pile design in permafrost. Canadian geotechnical journal, 18(3), 357-370.

22. Weaver, J. S., \& Morgenstern, N. R. (1981). Considerations on the use of cast-in-place piles in permafrost. Canadian geotechnical journal,, 17 (2), 320325.

23. G. H. Johnston, Permafrost: Engineering design and construction, 1st ed. (John Wiley \& Sons, Toronto, NY, 1981)

24. Morgenstern, N.R. \& Price, V.E.. (1965). The analysis of the stability of general slip surface. Gèotechnique. 15. 70-93.

25. Fomenko I. K. (2012) Current trends in slope stability calculations. Engineering Geology. № 6. pp. 4453.

26. 26 O. B. Andersland and D. M. Anderson, in Ground thermal regime. edited by R. L. Harlan and J. F. Nixon (McGraw-Hill, New York, NY,1978), pp. 103163.

27. Farouki, Omar. (1981). Thermal Properties of Soil. (series CRREL Monograph 81-1) (N.H.: U.S. Cold Regions Research and Engineering Laboratory, Hanover)

28. Nicolsky, Dmitry \& Romanovsky, Vladimir. (2018). Modeling long-term permafrost degradation: How fast permafrost can thaw?. Journal of Geophysical Research: Earth Surface. 123. 10.1029/2018JF004655. 